\title{
O CONSTITUCIONALISMO DE JOHN RAWLS: ELEMENTOS PARA A SUA CONFIGURAÇÃO*
}

\author{
JOHN RAWLS' CONSTITUTIONALISM: \\ CONFORMATION ELEMENTS
}

Cecilia Caballero Lois** Daniel de Lena Marchiori Neto****

RESUMO: O presente trabalho tem como finalidade verificar em que medida a obra do filósofo americano John Rawls pode ser configurada como uma Teoria da Constituição, capaz de auxiliar nas categorias justiça, liberdade e democracia. Para atingir esse objetivo, torna-se necessário efetuar as primeiras aproximações conceituais entre o discurso constitucional e a obra de John Rawls, com a finalidade metodológica de comprovar a idéia intuitiva de que os elementos de justiça são suficientes para entender a justiça como eqüidade como uma Teoria Constitucional, com valiosas contribuições ao constitucionalismo democrático.

PALAVRAS-CHAVE: John Rawls; Teoria da Constituição; Justiça como Equidade.

* Este artigo corresponde à primeira parte do quarto capítulo da minha tese de doutoramento defendida na Universidade Federal de Santa Catarina, sob orientação do Prof. Dr. Silvio Dobrowolski.

** Professora dos Cursos de Graduação e PósGraduação em Direito da Universidade Federal de Santa Catarina. Mestre e Doutora pela UFSC. Pesquisadora do CNPq.

*** Doutorando do Curso de Pós-Graduação em Direito da Universidade Federal de Santa Catarina.
ABSTRACT: This paper has the purpose to verify in what measure the work of the American philosopher John Rawls can be understood as a Theory of Constitution, capable to be related to the categories of justice, liberty and democracy. To reach that objective, it is necessary to start with the first conceptual approaches between the constitutional discourse and the work of John Rawls, with the methodological finality to prove the intuitive idea that the elements of justice are enough to understand the justice as fairness as a Theory of Constitution, with valuable contributions to the democratic constitutionalism.

KEYWORDS: John Rawls; Theory of Constitution; Justice as Fairness.

\section{INTRODUÇÃO}

É corrente na literatura a afirmação de que a teoria constitucional padece de uma "crise de racionalidade". De um lado, o modelo de Constituição-garantia, calcado numa concepção de sociedade que não mais existe, mostra-se insuficiente como ordem 
normativa apta a promover políticas distributivas e de justiça social. De outro, o modelo de Constituição-material viu-se profundamente abalado pela crise do Estado Social e da Constituição Dirigente, bem como pela ascensão do conservadorismo ultraliberal. Ambos os modelos, contudo, estão sendo revistos à luz dos fenômenos globalizantes e, principalmente, em face do advento do direito supranacional.

A Teoria Constitucional encontra-se, portanto, numa encruzilhada política e num momento de esgotamento teórico ocasionado pela falência dos pressupostos que a constituíram e, principalmente, pelo fato de jamais ter conseguido cumprir seus compromissos democráticos. Busca-se, assim, apresentar uma opção original de aproximação e superação dos modelos existentes. Sem romper com o liberalismo, deseja-se, no entanto, que essa opção represente uma possibilidade mais aberta, de modo a atender as demandas atuais e possibilitar o resgate da "vontade da Constituição".

Em face das necessidades apontadas, vai-se ao encontro da filosofia política e moral de John Rawls. Há que se esclarecer, inicialmente, que não se trata de conceber a teoria da justiça de Rawls como a panacéia para todas as controvérsias seculares que enfrenta a Teoria Constitucional. O que este artigo busca é apresentá-lo como autor de uma "teoria da Constituição", capaz de auxiliar o debate a partir das categorias justiça, liberdade e democracia.

Para atingir esse objetivo, torna-se necessário efetuar as primeiras aproximações conceituais entre o discurso constitucional e a obra de John Rawls, com a finalidade metodológica de comprovar a idéia intuitiva de que os elementos de justiça são suficientes para entender a justiça como eqüidade como uma Teoria Constitucional, com valiosas contribuições ao constitucionalismo democrático.

Desta forma, a caracterização da obra de Rawls como uma Teoria Constitucional exige alguns questionamentos: para se comprovar a hipótese central que move este trabalho seria necessária a presença, na obra do autor, de todos os elementos que compõem o âmbito material da Teoria da Constituição? O conceito de Constituição e direitos fundamentais (ainda que não seja essa a terminologia usada pelo autor) já seriam suficientes para caracterizar sua obra como uma Teoria Constitucional? As respostas, espera-se, serão oferecidas a seguir.

\section{A FORMAÇÃO DO PENSAMENTO CONSTITUCIONAL SEGUNDO JOHN RAWLS: ELEMENTOS CONSTITUCIONAIS ESSENCIAIS}

Inicialmente, deve-se ressaltar que a obra de Rawls apresenta claras referências ao constitucionalismo, entendido como requisito político e teórico necessário à possibilidade de formação de uma Teoria Constitucional. Tal assertiva pode ser confirmada a partir daquilo que ele denominou cinco princípios constitutivos do constitucionalismo.

Segundo Rawls (1995:220), esses elementos essenciais são o resultado de uma longa história de formação do pensamento constitucional, que teve início com a distinção efetuada por Locke entre poder constituinte e poder constituído (a). Logo após, aponta uma distinção hierárquica entre lei ordinária e lei superior (b); a Constituição democrática 
como a expressão do povo para governar-se a si mesmo (c); uma Constituição escrita que deve estabelecer os direitos fundamentais (d); e, finalmente, o fato de que o poder mais alto num Estado constitucional não pode pertencer nem ao executivo nem ao Tribunal Superior, deve ser um poder divido entre os três poderes e controlado pelo povo (e). ${ }^{1}$

Ocorre que a mera nomeação desses elementos não é suficiente. É imperioso verificar até que ponto estão coerentemente desenvolvidos na justiça como eqüidade. Nesse ínterim, quanto ao primeiro elemento, Rawls (1996: XXV) inicia destacando três fatos marcaram o rompimento com a antigüidade e o surgimento da filosofia moderna e, pode-se dizer, da filosofia constitucional, ${ }^{2}$ como espaço de reflexão pública numa sociedade que busca a emancipação:

O primeiro foi a reforma do século XVI. Este fato causou uma fragmentação da unidade religiosa vigente na Idade Média e levou ao pluralismo religioso, com grandes consequiências para os séculos posteriores. Isto, por sua vez, estimulou pluralismos de outras espécies, que foram uma característica da cultura no fim do século XVIII. O segundo é o desenvolvimento do Estado moderno, com sua administração central, no início regido por monarcas com grandes poderes, pode-se dizer, até, absolutos. E, se não eram absolutos, tentavam de qualquer maneira ser absolutos, da forma que fosse possível e ainda, que somente cediam parte de seu poder para a

1 Este artigo consiste justamente em verificar em que medida esses elementos não estão meramente nomeados, e sim trabalhados e desenvolvidos apropriadamente por Rawls, pois somente assim se poderá considerar a presença ou não de uma Teoria Constitucional. A conceituação desses elementos na obra de Rawls será feita nos momentos apropriados.

2 Para RAWLS, isso equivale aos trabalhos de Locke, Rousseau, Mill, Montesquieu, Kant, entre outros. aristocracia e a classe ascendente se fossem obrigados a fazê-lo ou fosse conveniente para seus interesses. O terceiro acontecimento histórico é o desenvolvimento da ciência moderna, que começa no século XVII.

Esses aspectos não se encontram isolados. Para o autor americano, "têm também uma importância decisiva outras controvérsias, tais como limitar ou não o poder dos monarcas absolutos mediante princípios constitucionais apropriados para tal, que protejam os direitos e as liberdades básicas" (RAWLS, 1996: XXVI). É esse conjunto de fatores que ele considera como a origem histórica do constitucionalismo e da Lei Fundamental.

Para Rawls (1996: 231), uma Constituição é a “expressão do poder constituinte enquanto poder do povo para estabelecer um novo regime, [e] estabelecer um marco para regular [através de uma Constituição] o poder ordinário". A dúvida que se coloca, neste momento, é, primeiro, se há uma teoria do poder constituinte, para depois averiguar quais valores e fundamentos esta teoria poderia invocar.

Para suscitar essa discussão, há que se partir do seguinte pressuposto: a escolha e $o$ processo de aplicação dos princípios da justiça e, por conseguinte, da Constituição, se confunde com o poder constituinte? Todas as evidências levam a crer que sim. Rawls deixa entrever uma teoria do poder constituinte na posição original, latente a partir da identificação dos princípios da justiça com o papel que os direitos naturais exercem na teoria tradicional do referido poder constituinte. Fica estabelecido, entretanto, que não se trata de equiparar princípios e direitos naturais. $\mathrm{O}$ que parece similar é a função destes elementos no estabelecimento de uma Constituição. Para Rawls (1997:12): 
A idéia norteadora é que os princípios da justiça para a estrutura básica da sociedade são o objeto do consenso original. São princípios que pessoas livres e racionais, preocupadas em promover seus próprios interesses, aceitariam numa posição inicial de igualdade como definidores dos termos fundamentais de sua associação. Esses princípios devem regular todos os acordos subseqüentes; especificam os tipos de cooperação social que se podem assumir e as formas de governo que se podem estabelecer. A essa maneira de considerar os princípios da justiça chamarei de justiça como eqüidade.

Deve-se chamar a atenção para o fato de que os princípios da justiça são apenas limites éticos ao poder de elaborar uma Constituição de caráter extrajurídico, não comprometendo a idéia de um poder ilimitado. O processo que o autor formula para a escolha dos princípios da justiça que devem reger a estrutura básica da sociedade, consta de quatro etapas, idéia que retira da história constitucional americana. A proposta é fazer, depois de adotados os princípios da justiça, uma convenção constituinte. Trata-se de um momento crucial, uma vez que as partes devem decidir qual a forma mais apta de elaborar uma Constituição. ${ }^{3}$

$\mathrm{Na}$ primeira etapa, na posição original, os princípios são escolhidos, após o que as partes na posição original se reúnem numa assembléia constituinte, na qual decidem sobre a justiça das formas políticas e escolhem uma Constituição. Esta é a segunda etapa, em que se estabelecem claramente os direitos e liberdades fundamentais. A partir de então é possível legislar -fazer leis que dizem respeito à estrutura econômica e social da sociedade: é a terceira etapa, em que se trata da justiça

3 Rawls refere-se à forma de elaborar a Constituição: se convenção constituinte, assembléia constituinte, mas, principalmente, extensão deste poder. das leis e das políticas econômicas e sociais. Quando esta se completa, já só nos resta, na quarta etapa, a aplicação das regras pelos juizes e outras autoridades (RAWLS, 1997:212).

O procedimento acima exposto deixa claro que Rawls prevê regras precisas para o funcionamento da convenção constituinte (e as etapas posteriores). Ainda que ele levante as mesmas objeções procedimentais em relação à escolha dos princípios da justiça, não é possível confundi-las. ${ }^{4}$ De fato, são os princípios de justiça que devem inspirar os direitos básicos do cidadão, bem como um sistema de escolha dos governantes e dos poderes constitucionais de governo. É neste estágio que se avalia a justiça dos procedimentos para lidar com as concepções políticas, levantando-se, parcialmente, o véu da ignorância.

Não se trata, pois, de um poder constituinte nos termos tradicionais, porquanto não pressupõe a constitucionalização dos direitos naturais, mas sim os princípios de justiça. Pode-se dizer, entretanto, que é, de fato, um poder de fazer uma Constituição, que inclui, ainda, algumas vantagens. Com efeito, ao sujeitar a Constituição aos princípios da justiça, Rawls propõe ao mesmo tempo um sistema ético de formulação e avaliação da Lei Fundamental, pois os princípios da justiça definiriam um critério de avaliação independente para o processo constitucional

4 Como afirma Vilhena (1999: 207): "trata-se de um momento ainda artificial, em que o véu da ignorância foi apenas parcialmente levantado, e as pessoas continuam a desconhecer suas características pessoais e econômicas, tendo informações exclusivamente gerais sobre o nível sócio cultural e econômico da sociedade e. logicamente, sobre os dois princípios da justiça". 
que assegura sua legitimidade em termos bem mais amplos que as teorias tradicionais.

Trata-se de uma teoria bem mais avançada que a própria teoria tradicional do poder constituinte, pois ao centrar a discussão na justiça, ele alcança um grau mais efetivo de legitimidade e, por conseguinte, de estabilidade. ${ }^{5}$ É outro ganho na teoria de Rawls: a Constituição será estável e duradoura, pois vem sustentada por numa concepção de justiça, amplamente aceita, o que permite afirmar, ser a Lei Fundamental, na concepção rawlsiana, quem cria seu próprio apoio, gerando sua base de legitimidade e garantindo sua permanência.

No que concerne ao poder reformador, é possível tomar os princípios de justiça justamente como os limites éticos ao poder de reforma da Constituição. De acordo com Rawls (1995:226), no tocante ao poder de emendar a Constituição, há que se considerar que "uma emenda nunca é algo isolado em si mesma, o objetivo que a move é ajustar os valores constitucionais básicos às mudanças de circunstâncias políticas e sociais ou incorporar à Constituição uma compreensão mais ampla destes valores". Segundo Cittadino (1999: 186), o que se depreende da argumentação de RAWLS é que "qualquer procedimento de reforma constitucional que venha desvirtuar a promessa inicial configurada na Constituição - revogar direitos fundamentais, por exemplo - não pode ser considerado válido".

5 E, isto surge das características de legitimidade nas quais se fundam os princípios da justiça. Importa na idéia de obediência à Constituição já que esta seria uma liberdade no momento que o indivíduo se submete às regras que ele mesmo elaborou.
Com efeito, Vieira (1999:222-224) demonstra que uma das grandes contribuições de Rawls estaria em afastar o problema da intangibilidade de algumas cláusulas da Constituição, sem precisar recorrer a quaisquer princípios outros que não possam ser justificados racionalmente através da ética e da superioridade dos direitos fundamentais, mas também sem resvalar para um naturalismo. ${ }^{6}$

\section{EM BUSCA DE UMA TEORIA DOS DIREITOS FUNDAMENTAIS EM JOHN RAWLS}

Ato contínuo à verificação da atuação constituinte chega-se ao conceito de Constituição em Rawls. Há que se ter presente, de início, que, para verificar-se se há, na justiça como eqüidade, efetivamente, uma Teoria Constitucional, é essencial a presença desse conceito associado a pelo menos dois elementos básicos que o compõem: direitos fundamentais e limitação do poder. Sem um conceito de Lei Fundamental que dê conta desses dois elementos, não há como se falar em Teoria da Constituição.

Uma rápida apreciação da obra de Rawls demonstra, contudo, que não há motivos para preocupação. O autor contempla com muita precisão o conceito de Constituição e afirma que a lei maior estaria composta pelo que denomina de elementos constitucionais essenciais.

Estes elementos são de duas classes: a) princípios fundamentais que especificam a estrutura geral do governo e o processo

6 Isto porque RAWLS é contratualista, mas não jusnaturalista. 
político: os três poderes legislativo, executivo e judiciário, o alcance da regra da maioria; e b) direitos e liberdades básicas a cidadania, em pé de igualdade que a maioria legislativa deve respeitar: exemplo, o direito de votar e participar na política, a liberdade de consciência, liberdade de pensamento e de associação, assim como as proteções do estado de direito (RAWLS, 1995: 217).

Com efeito, o conceito rawlsiano de Constituição está dado em congruência com o seu liberalismo. O autor não acata a compreensão material de Constituição (no sentido em que foi abordado neste trabalho) e prende a Lei Fundamental, exclusivamente, à defesa da liberdade. Segundo Rawls (1996: 337), "certamente, a história das Constituições que tiveram êxito, nos leva a pensar que os princípios para regular as desigualdades econômicas e sociais e outros princípios distributivos não são restrições constitucionais que devem ser incorporados a ela". Então, para se compreender a possível Teoria Constitucional de Rawls, "é importante notar que o autor estabelece uma hierarquia entre os dois princípios, sendo que a Constituição abriga o primeiro, e a legislação se responsabiliza pelo segundo" (VIEIRA, 1999:208). ${ }^{7}$

7 A diferença entre os princípios que condensam as liberdades básicas e os que condensam as desigualdades sociais e econômicas não reside no fato de que os primeiros expressam valores políticos e os segundos não. Ambos expressam valores políticos. Mas a diferença encontra-se em que a estrutura básica da sociedade tem funções distintas porém coordenadas. Os princípios que compreendem as liberdades básicas especificam o primeiro princípio, e os que compreendem o segundo as desigualdades sociais e econômicas. Essa diferenciação que Rawls faz, tem um sentido bastante cristalino: proteger a Constituição, pois a diferenciação entre os dois vai permitir que se resolvam muito mais facilmente os conflitos que envolvem o primeiro princípio do que os envolvem.
Em Uma Teoria da Justiça, o autor afirma textualmente: "na maior parte do tempo, discutirei a liberdade em conexão com as limitações legais e constitucionais. Nesses casos, a liberdade é uma certa estrutura de instituições, um certo sistema de normas públicas que definem direitos e deveres" (RAWLS, 1997: 219). Como se vê, para o autor, à época da sua primeira obra, o problema da liberdade não era efetivamente uma questão de definição, mas de compatibilização. Isso ocorre porque a idéia de liberdade em Rawls quer representar um sistema de liberdades (e não um conceito unívoco como se poderia apressadamente deduzir). Nesse contexto, o sistema é a idéia que representa o valor absoluto, pois cada liberdade pode ser ampliada ou restringida conforme a demanda do conjunto de direitos constitucionais.

O que se deve perquirir, uma vez que é fato nítido que são os direitos e as liberdades básicas que possuem garantia constitucional, é de que forma esse conjunto se 'articula' entre si, ou seja, se o que ele denomina de sistema corresponde ao que, na seara do constitucionalismo, denominou-se sistema de direitos fundamentais. Tal sistema é uma categoria de grande importância para a Teoria Constitucional, e não o fato de estar contemplada na justiça como eqüidade, se bem que não descartaria a possibilidade de seguir adiante este trabalho, pelo menos furtaria em grande parte o seu interesse.

Na acepção de Miranda (1998:28), a idéia de sistematicidade de uma Constituição determina que ela deva ser apreendida, a qualquer instante, como um todo, na busca de uma unidade e harmonia de sentido. "O apelo ao elemento sistemático consiste em procurar as recíprocas implicações dos 
preceitos e dos em que aqueles fins se traduzem, em situá-los, e defini-los na sua inter-relação e em tentar, assim, chegar a uma idônea síntese globalizante, credível e dotada de energia normativa". Tem-se idêntica interpretação no caso dos direitos fundamentais: a sistematicidade implica a existência (ou não) de uma unidade ou harmonia na definição, conjugação, restrição e interpretação de cada direito em relação ao outro. Um sistema surge, portanto, quando os direitos e liberdades básicas não são enfocados de forma isolada, mas de forma a se compatibilizarem racionalmente entre si. $\mathrm{O}$ que se tenta saber agora, portanto, é se Rawls compreende as liberdades dessa forma.

Inicialmente, foi visto como Rawls define os direitos fundamentais como as liberdades básicas; tais liberdades estão conectadas entre si, formando uma unidade; finalmente, cada uma dessas liberdades requer uma individualização. Visto assim, o conjunto de direitos idealizado por Rawls adquire as características de um verdadeiro sistema de direitos fundamentais que encerra uma teoria desses direitos, pois procura uma forma racional que justifique a distribuição, o que desenvolve ao longo de suas duas obras.

Entretanto, ele não teria uma teoria dos direitos fundamentais, como foi afirmado, caso não se preocupasse com as restrições aos direitos, não somente pelos procedimentos (como efetivamente faz), mas, principalmente, pelos outros direitos do sistema constitucional. Há que se perguntar, neste momento, se a restrição aos direitos - não mais, então, por mecanismos procedimentais, mas, pelo próprio direito - gera, tal como no caso anterior, uma ameaça à esfera de atuação dessa liberdade e, portanto, uma injustiça.
Isso equivale a perguntar-se o que segue: pode o direito limitar o próprio direito, sem ferir a liberdade?

Com efeito, no tocante à redução do alcance dos direitos fundamentais, Rawls constata que o direito pode limitar o direito desde que seja para garantir a liberdade. Todas as outras limitações são incompatíveis com a justiça como eqüidade. Assim, se o autor só admite restrições à liberdade para o bem da liberdade, o único motivo para circunscrever as liberdades básicas e torná-las menos abrangentes é que, caso contrário, elas interfeririam umas nas outras. Por isso mesmo, a garantia da liberdade e da justiça exige que o sistema de direitos fundamentais se organize a partir do pressuposto de que, com aquele determinado arranjo, será obtida a maior liberdade possível, dentro do quadro constitucional; assim, a melhor ordenação das várias liberdades depende da totalidade das limitações a que elas estão sujeitas (RAWLS, 1997: 220).

Duas questões, neste momento, merecem destaque. Por um lado, há que se chamar a atenção para o fato de a teoria da liberdade de Rawls ter sido considerada liberal demais leia-se negativa no sentido da liberdade negativa - e poderia levar à seguinte objeção:

toda recusa ou limitação das liberdades é injusta, que é um mal, sem que se possa precisá-lo. (...) Uma tal presunção acaba pondo no mesmo plano a liberdade de expressão e a liberdade de passar férias na Côte d'Azur! Ela não nos permite saber quais liberdades são importantes, por quê, a que título, etc. em nome da "liberdade negativa" dos cidadãos. Ao contrário, parte-se da premissa de que a liberdade política é um bem intrínseco do qual as outras liberdades necessitam para se realizar, reencontra-se uma coerência e uma linha mestra para julgar tanto as ações dos 
Estados quanto os comportamentos individuais (AUDARD, 1989:420).

As críticas de Audard deixam bastante claro que sua teoria deve ser lida no contexto de uma sociedade liberal e democrática, quando determinadas condições políticas, econômicas e sociais estão garantidas, e não de uma forma universal como ele pretende. A resposta de Rawls virá somente em textos posteriores e será melhor delineada em O Liberalismo Político quando, bastante a contragosto, reconhece que um sistema de liberdade desse tipo é algo poucas sociedades podem se permitir.

No mesmo sentido, aparece uma importante objeção de Hart (1975: 230-252), que condena o professor americano por ter usado uma noção muito estreita de liberdades básicas $^{8}$, acusando-o, ainda, de não justificar o motivo pelo qual as partes escolheriam a prioridade das liberdades.

As críticas de Hart foram decisivas para a mudança drástica da fundamentação da obra de Rawls. Isso ocorreu porque o autor de Uma Teoria da Justiça, logo após os comentários do jurista inglês, viu-se obrigado a admitir o que estava implícito e todos já sabiam sobre o seu trabalho: que ele escolhia e não justificava a prioridade e nem a larga extensão de todas as liberdades. O que ele desejava era que seu sistema fosse compatível com todos os outros sistemas (principalmente, os socialistas), e não somente com os sistemas

8 Embora partam de pressupostos diferentes, tanto as críticas de Audard como as de Hart e Dworkin têm o mesmo sentido: o conceito de liberdade de Rawls é insuficiente/ deficiente. Se esta questão não ataca o fato de que a Constituição permanece como albergue dos direitos da liberdade, altera a idéia de sistema de direitos fundamentais em Rawls. políticos de cunho liberal. Paradoxalmente, porém, acabou tornando-se liberal demais, o que conferiu à sua teoria um caráter absolutamente particular. ${ }^{9}$

$\mathrm{O}$ autor concorda com a maioria das críticas que lhe foram dirigidas e, como sempre, propõe-se corrigir e (ou) responder às deficiências apontadas. A primeira deficiência, acredita Rawls (1996: 299-300), pode ser corrigida a partir de uma revisão no conceito de pessoa e na concepção de cooperação social, o que ele faz mediante os conceitos de racional e razoável e que equivale, portanto, a compatibilizar a liberdade com a igualdade e assim levar o liberalismo a um avanço importante.

Além disso, é de suma importância as respostas às críticas que acusaram Rawls de negar a prioridade de algumas liberdades em relação a outras, já que se depreende de Uma Teoria da Justiça que o critério para distribuição das liberdades é meramente quantitativo e não leva em consideração os diversos níveis de relevância e importância das liberdades. Nesse momento, Rawls constrói, ao largo do Liberalismo Político, uma 'lista' das liberdades que considera prioritárias. ${ }^{10}$

Essa lista, que não é exaustiva, vai ganhando contornos cada vez mais precisos nos momentos posteriores (quando da aplicação concreta da liberdade nos estágios

9 Esta não é a opinião de Dworkin, que, contrariamente, o acusou de ser liberal de menos.

${ }^{10}$ Liberdade de consciência, de pensamento, expressão, associação, propriedades pessoais, e, ainda, uma liberdade que ele considera importante, embora não se situe no rol das liberdade mais tradicionais aos liberais: a liberdade política de participação igual, pois ele a vê como um importante instrumento de garantia das outras liberdades. 
constitucional, legislativo e judicial). Ele não deixa de reconhecer, porém, na sua obra mais atual, que há aquelas que são efetivamente prioritárias: ou porque representam a capacidade moral do indivíduo ou porque garantem a participação política igual. Demonstra então, claramente, a existência de uma teoria dos direitos fundamentais. Ao abandonar a idéia de que é a simples necessidade de compatibilizar os direitos entre si que funda o sistema e, por consequiência, estabelecer critérios para isso, Rawls permite afirmar taxativamente a compatibilidade de seus desígnios com os da Teoria da Constituição. Tal como se viu, os critérios são, fundamentalmente, dois. O primeiro é a participação igual, participação essa que teria uma função bem mais relevante, pois serviria para assegurar todas as outras.

Dos critérios citados anteriormente, é o segundo que estabelece a diferença entre a liberdade e o valor da liberdade. De fato, nesse momento, Rawls vê-se obrigado a retomar uma distinção já efetuada em Uma Teoria da Justiça (e que lá passou despercebida), que tem como objetivo demonstrar, ao mesmo tempo, que sua teoria não padece dos vícios do liberalismo mais conservador, embora seja uma teoria totalmente liberal e, por outro lado, que é perfeitamente lícito tratar-se a Constituição como o locus exclusivo da liberdade, sem que isso seja uma atitude 'meramente formal'.

Dessa forma, segundo ele, quando as condições materiais são desfavoráveis, não decai a liberdade, mas o valor que lhe é aferido. E vice-versa: quando as necessidades sociais estão satisfeitas, aumenta o valor da liberdade, mas a liberdade-como prerrogativa constitucional - sempre permanece a mesma. Rawls nega, portanto, a partir dessas diferenças, o fato de que as liberdades que ele estabelece sejam puramente formais, pois a participação igual e o segundo princípio estariam à altura de oferecer-lhes um conteúdo substancial. Pode-se reafirmar, aqui, uma das premissas deste trabalho. Rawls tem uma Teoria Constitucional implícita que, apesar de não romper com o liberalismo, encontra mecanismos de atualização e materialização, mediante a sustentação do conceito de Constituição justa.

Outra questão bastante polêmica que retorna à pauta de Rawls, como decorrência das críticas recebidas, diz respeito à distinção entre regulação e restrição de direitos. $\mathrm{O}$ autor acredita que, embora sendo essa uma demanda importante dentro de um sistema de direitos fundamentais, não foi tratada de forma condizente na sua primeira obra. $\mathrm{O}$ que parece, entretanto, é que, devido às transformações que sofreu a sua compreensão de liberdade, o autor gostaria de dar um novo alcance a essa distinção.

Com efeito, de acordo com o que ele chamou de critério quantitativo, a restrição de uma liberdade - que talvez não fosse tão importante - poderia afetar o âmbito de abrangência de uma liberdade mais relevante. Assim, o que Rawls deseja é que a organização/ restrição das liberdades seja efetuada em se considerando não só a prioridade da liberdade, mas a prioridade de algumas liberdades sobre as outras. A única regra seria que se deve garantir a ordenação das liberdades de forma a assegurar a liberdade igual, a liberdade por excelência. 


\section{VALIDADE E ABRANGÊNCIA DOS DIREITOS FUNDAMENTAIS NA TEORIA CONSTITUCIONAL RAWLSIANA}

Finalmente, deve-se enfrentar, agora, uma das mais delicadas temáticas referentes à teoria dos direitos fundamentais de Rawls: a validade - o âmbito de abrangência - dos direitos e liberdades básicas como resultado/ decorrência do contrato social. A questão pode ser (mais ou menos) assim colocada: se os direitos inseridos na Constituição são decorrência dos princípios escolhidos na posição original, parece mais do que evidente que devam possuir as mesmas características, a saber, a generalidade e a universalidade de suas proposições.

Disso decorre, para o autor, que os direitos fundamentais devem ter uma validade universal, pois são o resultado direto da capacidade moral dos indivíduos ${ }^{11}$, não estando, portanto, sujeitos a nenhum tipo de particularismo; também são, por isso mesmo, direitos gerais, pois se aplicam a todos os indivíduos indistintamente. Assim, "a validade dos direitos liberais pode ser reivindicada, em nome de valores que dizem respeito a uma natureza humana em geral, idéia esta que por si mesma não determina nenhuma forma específica de vida" (VITA, 1993: 113). Essa validade ou abrangência dos direitos fundamentais denomina-se validade transcultural dos direitos e traz uma série de tópicos relevantes para a discussão da Teoria Rawlsiana da Constituição.

Com efeito, os comunitaristas colocam como desafio endêmico às democracias

${ }^{11}$ E, nesse sentido, são todos iguais: têm uma concepção de bem e um senso de justiça. liberais a necessidade de reconhecimento do multiculturalismo e da política da diferença. Para os comunitaristas, "reconhecer e tratar como iguais aos membros de certos grupos é algo que hoje parece requerer que as instituições públicas reconheçam, e não que atropelem, as particularidades culturais, pelo menos no que se refere àqueles de cuja compreensão de si próprios depende a durabilidade de sua cultura" (GUTMANN, 1993: 16). De acordo com os comunitários, contudo, o que se vê nas democracias atuais, que são notoriamente liberais, é o fato de serem elas movidas por uma 'cegueira' em relação a essas diferenças.

Para os comunitaristas, a idéia da dignidade da pessoa humana, da qual provêm todos os direitos liberais contemporâneos, se considerada em termos universalistas do 'eu', como efetivamente está colocada, não vale nada (TAYLOR, 1993: 62-63). Quer isso dizer que, para os antiindividualistas, se todos têm direito à dignidade ou, pelo menos, à mesma forma de serem considerados dignos, acaba por estabelecer-se o padrão universal de dignidade/igualdade - homem/branco/ urbano/eurocêntrico - que exclui os que não se encaixam no padrão. Trata-se, portanto, para os autores em tela, de substituir a cultura da igualdade pela cultura da diferença ou, em outros termos, de atualizar o liberalismo, segundo as exigências da era contemporânea.

Por outro lado, comunitaristas como Taylor (1993:93) acusam o liberalismo de sustentar-se numa falsa neutralidade, já que seria impossível manter-se uma rigorosa neutralidade. Segundo eles, o liberalismo não é nem pode ser compatível com todos os meios de vida, o que fica provado pela supremacia da religião em algumas 
comunidades onde não há como se falar em liberdade de expressão, já que a religião em si é a essência da liberdade. ${ }^{12}$ Já os liberais, como Rawls e Dworkin refutam esse tipo de argumento, afirmando que a neutralidade procurada é a de procedimentos, não de valores, e que os comunitários se recusam a perceber essa diferença. ${ }^{13}$ A essa alegação, os comunitários respondem dizendo que a neutralidade seria, ainda, em si mesma, uma opção pelo padrão dominante e, portanto, insuficiente. Por sua vez, os universalistas afirmam que, não fossem as liberdades liberais (a de associação seria uma delas), as comunidades nunca seriam possíveis.

Independentemente de poder ou querer esgotar este debate - o que parece realmente inimaginável-buscou-se, até aqui, demonstrar os diversos matizes que ele assume. $\mathrm{O}$ que importa, para os fins deste trabalho, contudo, é saber se os limites apontados pelos comunitaristas à Teoria Rawlsiana da Constituição, especialmente à teoria dos direitos fundamentais, podem comprometê-la seriamente ou se, pelo contrário, a Teoria Rawlsiana pode considerar-se fortalecida através das críticas. E, antes de mais nada, é importante esclarecer que, de acordo com o que foi exposto, o que se pretende é examinar as possibilidades de escolha, avaliando se é democrático ou não que determinados grupos,

12 Os exemplos mais utilizados são o dos índios, o dos versos satânicos e o da comunidade franco-parlante no Canadá.

${ }^{13}$ Um bom exemplo é o princípio da diferença em Rawls: o lugar de destaque que ocupa em seu sistema determina, ainda que de forma implícita, a existência de valores como a solidariedade e a presença de fortes laços sociais; se não fosse assim, a simples menção a esse princípio sequer seria possível. em vista de sua filiação a uma determinada comunidade, ou por pertencerem a uma "categoria" especial, mereçam que se lhes atribuam direitos especiais, em detrimento muitas vezes dos direitos individuais.

Sem dúvida, a obra de Rawls (tanto como a de Dworkin, por exemplo) encarna um individualismo dos direitos pessoais, que parece ser a melhor configuração que uma Teoria Constitucional pode assumir. De fato, no tocante, especificamente, à Teoria Constitucional, a idéia de que a validade dos direitos fundamentais se sustenta em critérios universais, resulta muito mais segura e compatível com a democracia constitucional.

Com efeito, na Teoria Rawlsiana dos direitos fundamentais, fica claro que ela atinge uma possibilidade de consolidação dos direitos e liberdades que outras teorias não conseguem atingir. E mais, se compreendida adequadamente, poder-se-á perceber que o autor não recusa a possibilidade de valores particulares, apenas diz que a Constituição, que é vinculada à sua universalidade, é o lugar da liberdade. Por outro lado, deve-se entender que a idéia de uma concepção política de justiça é associada à subscrição de valores mínimos, que são o conteúdo do overlapping consensus: e justamente por serem valores mínimos, é que se podem considerar transculturais e objetos de um consenso. Tais valores seriam a justiça distributiva, a liberdade, a igualdade, a proteção aos direitos humanos e o império da lei.

Rawls não nega em momento algum a existência de valores democráticos secundários e que seriam relevantes em casos locais, como, por exemplo, nações compostas de muitas minorias. A questão está ainda em perceber que nenhum ideal democrático pode 
ser um ideal fechado em si mesmo. Os valores primários sempre devem deixar espaço à realização de valores secundários. Se entendida de uma forma adequada, a teoria da justiça liberal não se contrapõe a comprometimentos duradouros nem a valores secundários. Para Rawls, este conflito está assentado em uma falácia, pois contextualização e universalização não são necessariamente princípios conflitantes.

\section{A LIMITAÇÃO E ORGANIZAÇÃO DO PODER POLÍTICO}

Além dos elementos constitucionais essenciais, é necessário verificar a forma como o autor contempla outro dos elementos centrais do constitucionalismo, que é uma das funções primordiais da Constituição: a limitação $e$ organização do poder político. Nesse sentido, a primeira observação a ser efetuada é a de que Rawls se aproxima da Teoria Constitucional, não porque sustenta a mera defesa da limitação do poder, mas, especialmente, porque o faz por meio de mecanismos constitucionais, tanto em Uma Teoria da Justiça quanto no Liberalismo Político.

Essa temática assume uma grande relevância em Rawls, pois a limitação do poder político mediante o império da lei (rule of $(a w)^{14}$ tem para ele a função de dar substantividade aos princípios da justiça, já

${ }^{14}$ Kukathas e Pettit (1995: 36) afirmam que o império da lei [em Rawls] "é geralmente contraposto ao domínio de uma governação caprichosa; pretende-se com essa expressão significar uma organização em que todos são iguais perante a lei e todos sabem qual a sua situação perante a lei, sabendo o tratamento que podem esperar se assumirem um comportamento ou outro. Trata-se das condições para garantir o legítimo exercício do poder político que equivale à teoria da legitimidade do poder político". que "a vida política, as instituições políticas, estão dentro do pensamento de Rawls a serviço dos direitos fundamentais dos cidadãos e têm como objetivo garantir um marco constitucional que possibilite a cada indivíduo ou grupo ir constituindo o que ele considera vida boa" (ALTABLE, 1995: 125). Para isso, o Estado precisa manter-se, como já foi dito, neutro às pretensões de quem quer que seja. Para a Teoria Constitucional Rawlsiana, a idéia de limitação e organização do poder político é sempre, portanto, uma questão de legitimidade e justiça.

Em Uma Teoria da Justiça, a questão dos requisitos para garantir a legitimidade do Estado constitui-se uma parte bastante restrita da obra, e, portanto, o autor não faz grandes considerações em relação ao assunto. Limitase a dizer que devem ser adotados, ainda na convenção constituinte e sob o véu da ignorância, porquanto, seriam decorrentes da escolha efetuada na posição original, certas restrições (que podem ser à atuação do Estado, à regra da maioria ou aos Tribunais) cuja função principal é garantir que o princípio da liberdade igual não seja sabotado por sua própria regulamentação.

Para Rawls, o controle dos poderes deve ser efetuado pelos mecanismos tradicionais do constitucionalismo: bicameralismo, separação de poderes conjugada com um sistema de freios e contrapesos, um sistema de representação eqüitativo, o acesso equânime - pelo menos em caráter formal - a todos os cargos eletivos ou públicos, a existência de princípios genéricos e de aplicação universal e, finalmente, uma carta de direitos corretamente aplicada pelos tribunais. A estes últimos requisitos é que o autor denomina de justiça como regularidade ou justiça formal. 
Em Uma Teoria da Justiça, ainda, Rawls expressa a necessidade de mecanismos relevantes que devem ser incorporados ao sistema constitucional. Tais mecanismos estão presentes desde a origem do constitucionalismo, com a função de preservar a legitimidade do poder político do Estado. Segundo o autor, esses procedimentos servem para limitar a extensão da participação igual sem comprometer a liberdade política igual. E são de três tipos: restrição do alcance da regra da maioria, ou seja, as questões que a maioria não pode tocar; ${ }^{15}$ previsão de mecanismos para estipular um estado de exceção, visando à proteção da liberdade e, finalmente, uma estrutura política que possa patrocinar, mediante um processo político justo, uma distribuição de recursos imparcial para evitar que "as desigualdades do sistema socioeconômico possam solapar qualquer igualdade política que possa ter existido em condições historicamente favoráveis" (RAWLS, 1997: 247).

Objetivamente, se pensada unicamente a partir dos mecanismos de defesa das suas

15 Rawls inova nesse momento, verificando de que forma essas limitações são compatíveis com a justiça como eqüidade. Assim, para ele, fica claro, já na convenção constituinte: a restrição na liberdade deve servir para assegurar a própria liberdade. Tal como se verá em seguida, trata-se de limites à reforma da Constituição. Aqui pode-se expressar uma das maiores dificuldades encontradas na formulação deste trabalho. Pelo fato da formação de uma Teoria Constitucional ser um trabalho de reconstituição e esses conceitos estarem dispersos na sua obra, muitas vezes foi preciso desmembrá-los, pois o autor os usa para trabalhar várias questões em sua obra. Assim, ainda que em determinado momento eles pareçam incompletos, alguns deles serão retomados mais adiante. Este é o caso da regra da maioria que está presente nas discussões sobre o controle de constitucionalidade em Rawls e nas discussões sobre a democracia constitucional. instituições, a teoria da proteção da Constituição, em Uma Teoria da Justiça, não é muito determinada. O fato não é surpreendente, uma vez que, de acordo com a tradição constitucional americana, em que os mecanismos já existentes na tradição liberal são suficientes para conter os abusos do poder. É por isso que a principal preocupação é para com os princípios: eles devem guiar a legislação e as práticas decisórias que devem representar as convicções sobre o que é justo ou injusto em um determinado momento político.

Não é o caso, entretanto, do Liberalismo Político. Aqui, embora a afirmação possa causar perplexidade e surpresa, é possível dizer que o sentido global dessa obra é o de uma teoria da limitação e legitimidade do poder político. Para compreender a extensão da assertiva, há que se ter em mente as críticas efetuadas ao trabalho de Rawls: como é possível sustentar uma doutrina abrangente e ao mesmo tempo sustentar que não seria razoável utilizar o poder do Estado para que todos os que não a sustentam não a ataquem? Para o autor, a idéia de se sustentar como fundamental uma única doutrina abrangente é equivalente ao totalitarismo e, portanto, a um exercício desmedido do poder coercitivo do Estado.

A questão subjacente no Liberalismo Político é que o fato do pluralismo (especialmente o pluralismo razoável) implica, necessariamente, a limitação e a legitimidade do poder político e, embora isto não esteja, textualmente, formulado na sua obra. Com efeito, considerando-se os principais elementos que compõem o Liberalismo Político, o conceito de razoável, a idéia de burdens of judgment (limites 
do juízo), a função de razão pública e overlapping consensus, verificar-se-á que todos confluem para a tentativa da limitação do poder político, pois somente um poder limitado é um poder legítimo.

Pode-se dizer, inclusive, que a concepção política de justiça é uma teoria da limitação justa (porque legítima) do poder político. De fato, o pluralismo não pode existir sem limites ao poder: "onde existe uma pluralidade de doutrinas razoáveis, é irracional, ou ainda pior, desejar utilizar sanções advindas do poder do Estado para corrigir ou castigar aqueles que não estariam de acordos com nossas opiniões" (RAWLS, 1996: 138).

Várias são as conclusões que podem ser extraídas. Primeiro, há que se perceber que, para Rawls, o Estado é associação constituída por cidadãos livres e iguais. Sua função primária é regulamentar e garantir a busca dos interesses morais (a realização racional do bem) de cada indivíduo, na maioria das vezes, determinado pela teoria abrangente que subscrevem. Ocorre que o autor estipula um único limite para a realização desse bem: o da prioridade da justiça. O papel do Estado seria, então, garantir o pluralismo razoável inerente a uma sociedade liberal, exercendo este poder no único e exclusivo sentido de preservar os princípios da justiça e dentro dos limites do overlapping consensus -este subordinado ao exercício do poder político.

Ainvestigação do entendimento rawlsiano a respeito do exercício do poder político, suas relações com a liberdade e legitimidade, não estaria completa se não se mencionasse o fato de que, neste momento, o autor retoma os termos de Rousseau e Kant: a liberdade consiste em agir de acordo com a lei que o povo criou para si mesmo, porém, no caso de
Rawls, a liberdade e a legitimidade do poder estariam em agir de acordo com os princípios da justiça que os indivíduos se deram a si mesmos. Do fato de os princípios serem legítimos e todos esperem que todos se comportem da mesma forma, aparece, então, a idéia de Rawls: o poder coercitivo só pode ser exercido quando estão em jogo os elementos constitucionais essenciais e os principais arranjos das instituições básicas da justiça, ou seja, os dois princípios da justiça.

\section{CONSIDERAÇÕES FINAIS}

Do até aqui exposto, ficou claro que a justiça como eqüidade contém os seguintes elementos constitucionais: a) definição do constitucionalismo como movimento histórico de limitação do poder; b) enunciação dos conceitos essenciais do constitucionalismo; c) preocupações 'constituintes'; d) conceito de Lei Fundamental, entendida como Constituição-Garantia; e, finalmente, e) teoria dos direitos fundamentais. Além disso, contempla uma teoria da limitação do poder político a partir da noção de overlapping consensus.

Uma avaliação inicial permite afirmar que, se considerada diante do impacto que foi o advento da Constituição material, o conceito de Rawls é bastante limitado e até mesmo conservador, mesmo considerando que o Estado deve ser (em alguma medida) distributivo ou até mesmo interventor (aliás, Rawls nega que seu Estado seja um mínimo nos termos, por exemplo, de Nozick), pois não cabe à Constituição fornecer os instrumentos para tal, cabe, antes, contê-los. Se lido, entretanto, de um ponto de vista liberal, podese dizer, por outro lado, que o autor propõe um avanço considerável. Ele reconhece que 
a realização da liberdade exige muito mais que a própria liberdade, reclama que se reconheça o seu valor, mas considera que é esta uma tarefa da legislação. Ao fazer isso, reduz e fortalece a Constituição, concomitantemente, pois, de um lado impede que seja desconsiderada cada vez que a justiça distributiva não se realiza, mas, por outro, assegura muito mais eficazmente o indivíduo, garantindo-lhe a certeza da liberdade.

Não se quer, neste momento, fazer uma apologia da Constituição mínima. Propõe-se, ao contrário, a defesa dos direitos constitucionais à igualdade; trata-se, efetivamente, de uma das principais conquistas da democracia recente e, negá-los, acredita-se que seja um dos mais 'problemáticos' aspectos da Teoria Rawlsiana da Constituição. Pois, embora considerada a distinção conceitual entre liberdade e valor da liberdade bem como a idéia de que, localizados na legislação infraconstitucional, os direitos sociais terminam por proteger a Constituição, não consegue mascarar que seu conceito de Constituição é formal, muito semelhante, inclusive aos de Jellinek ou Kelsen. Basta lembrar a crença desses juristas na possibilidade de submeter a vida do Estado a um ordenamento jurídico que contenha os direitos fundamentais, sendo que, além dessa característica, o que determina o seu caráter de lei fundamental é o fato de ser o fundamento de toda ordem jurídica.

O sentido que Rawls dá à Constituição não é muito diferente. O que o distancia deste novo modelo liberal é que, para o professor americano, toda a vida do Estado deve ser guiada pelos princípios da justiça que informam a concepção pública da justiça (conteúdo do overlapping consensus) e, por sua vez, delimita e submete a atuação do poder público a sua observância. Pode-se alegar que o fato de submeter a limites de justiça aproxima esta Constituição de uma Constituição material. Intuitivamente, a resposta parece contradizê-lo, pois, inclusive, este não seria o desejo nem a concepção de Rawls. Esta será, contudo, uma discussão $a$ posteriori, uma vez que algumas questões conceituais pertinentes ficaram por discutir.

\section{REFERÊNCIAS}

ACKERMAN, Bruce. La Política del diálogo liberal. Traducción de Gabriela L. Alonzo. Barcelona: Gedisa, 1999. (Série Cla-de-ma Derecho/Filosofía del Derecho).

ALTABLE, María Pilar González. Liberalismo vs. Comunitarismo (John Rawls: una concepción política del bien). In: Doxa. Cuadernos de Filosofía del Derecho. n. 17-18. Madrid: Universidad de Alicante, 1995. p. 117-136.

AUDARD, Catherine. Introdução: John Rawls e o conceito do político. In: RAWLS, John. Justiça e democracia. Tradução de Irene A. Paternot. São Paulo: Martins Fontes, 2000. (Coleção Justiça e Direito). p. XIII-XXXVII.

BARRY, Brian. La Justicia como imparcialidad. Traducción de José Pedro Tosaus Abadía. Barcelona/Buenos Aires: Ediciones Paidós Ibérica, 1997. (Paidós Estado y Sociedad, n. 39).

BARRY, Brian. Teorías de la justicia. Traducción de Cecilia Hidalgo, com la colaboración de Clara Lourido. Barcelona: Editorial Gedisa, 1995. (Colección Hobre y Sociedad).

CITTADINO, Gisele. Pluralismo, direito e justiça distributiva - elementos da filosofia constitucional contemporânea. Rio de Janeiro: Editora Lumen Juris, 1999.

CHUEIRI, Vera Karam. Filosofia do direito e modernidade: Dworkin e a possibilidade de um discurso instituinte de direitos. Curitiba: JM editora. 1995. 
DANIELS, Norman (editor). Reading Rawls critical studies of A Theory of Justice. New York: Basic Books, 1973.

DANIELS, Norman (editor). Equal liberty and unequal worth of liberty. In: DANIELS, Norman (editor). Reading Rawls - critical studies of A Theory of Justice. New York: Basic Books, 1973. p. 253-281.

GUILLARME, Bertrand. Rawls et le libéralisme politique. In: Revue Française de Science

Politique. Volume 46: Pluralisme, Justice, Égalité - de lémpirique au philosophique dans l'étude de la démocratie, n. 2, abr. 1996. p. 321-343.

GUTMANN, Amy. Introducción, In: TAYLOR. Charles. El Multiculturalismo y "La política del reconocimiento". Traducción de Mónica Utrilla de Neira. México: Fondo de Cultura Económica, 1993(a).

HART, H. L. A. Rawls on liberty and its priority. In: DANIELS, Norman (editor). Reading Rawls critical studies of A Theory of Justice. New York: Basic Books, 1973. p. 230-252.

KATEB, George. La Individualidad democrática y el significado de los derechos. In:

ROSENBLUM, Nancy (dir.). El Liberalismo y la vida moral. Traducción de Horacio Pons. Buenos Aires: Ediciones Nueva Visión, 1993. (Colección Cultura y Sociedad). p. 203-226.

RAWLS, John. Collected papers. Edited by Samuel Freeman. Cambridge/London: Harvard University Press, 1999.

RAWLS, John. Justicia como equidadmateriales para una teoria de la justicia. Traducción Miguel Ángel Rodilla. Madrid: Editorial Tecnos, 1986. (Biblioteca Universitaria).
RAWLS, John. Liberalismo político. Traducción de Sergio René Madero Báez. México: Fondo de Cultura Económica, 1996.

RAWLS, John. Political liberalism (with a new introduction and the "Reply to Habermas"). New York: Columbia University Press, 1996. (John Dewey essays in philosophy: n. 4).

RAWLS, John. Uma Teoria da justiça. Tradução Almiro Pisetta e Lenita M. R. Esteves. São Paulo: Martins Fontes, 1997. (Coleção Ensino Superior).

VIEIRA, Oscar Vilhena. A Constituição e sua reserva de justiça - um ensaio sobre os limites materiais ao poder de reforma. São Paulo: Malheiros Editores, 1999.

VITA, Álvaro De. A Justiça igualitária e seus críticos. São Paulo: Editora UNESP, 2000.

(Biblioteca Clássica).

VITA, Álvaro De. A Tarefa prática da filosofia política em John Rawls. In: Lua Nova - Revista de cultura e política. São Paulo: CEDEC, 1992, n. 25 , p. 5-24.

VITA, Álvaro De. Justiça liberal - argumentos liberais contra o neoliberalismo. Rio de Janeiro: Paz e Terra, 1993.

WALZER, Michael. Comentario. In: TAYLOR, Charles. El Multiculturalismo y "La política del reconocimiento”. Traducción de Mónica Utrilla de Neira. México: Fondo de Cultura Económica, 1993. p. 139-146.

WOLF, Suzan. Comentario. In: TAYLOR, Charles. El Multiculturalismo y "La política del reconocimiento". Traducción de Mónica Utrilla de Neira. México: Fondo de Cultura Económica, 1993. p. 108-122. 